Deciphering Multiple Critical Parameters of Polymeric Self-Assembly by Fluorescence Spectroscopy of a Single Molecular Rotor BODIPY-C12

\title{
Lisitsyna, Ekaterina
}

2021-01-26

Lisitsyna, E, Efimov , A, Depresle , C , Cauchois, P, Vuorimaa-Laukkanen, E, Laaksonen, T \& Durandin , N 2021 , ' Deciphering Multiple Critical Parameters of Polymeric Self-Assembly by Fluorescence Spectroscopy of a Single Molecular Rotor BODIPY-C12 ' , Macromolecules, vol. 54 , no. 2 , pp. 655-664 . https://doi.org/10.1021/acs.macromol.0c02167

http://hdl.handle.net/10138/338293

https://doi.org/10.1021/acs.macromol.0c02167

acceptedVersion

Downloaded from Helda, University of Helsinki institutional repository.

This is an electronic reprint of the original article.

This reprint may differ from the original in pagination and typographic detail.

Please cite the original version. 


\title{
Deciphering multiple critical parameters of
}

\author{
polymeric self-assembly by fluorescence
}

spectroscopy of a single molecular rotor BODIPY-

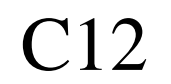

Ekaterina Lisitsyna ${ }^{a,{ }^{*},}$, Alexander Efimov ${ }^{a}$, Clémentine Depresle ${ }^{a, c}$, Pierre Cauchois $^{a, d, \dagger}$, Elina Vuorimaa-Laukkanen ${ }^{a}$, Timo Laaksonen, ${ }^{a, b}$, Nikita Durandin, ${ }^{a,}{ }^{*}$

${ }^{a}$ Faculty of Engineering and Natural Sciences, Tampere University, Korkeakoulunkatu 8, 33720

Tampere, Finland

${ }^{\mathrm{b}}$ Drug Research Program, Division of Pharmaceutical Biosciences, Faculty of Pharmacy, University of Helsinki, FI-00014 University of Helsinki, Finland

'INSA Rouen Normandie, 685 Avenue de l'université, 76800 Saint-Etienne-du-Rouvray, France

${ }^{\mathrm{d} E c o l e ~ N a t i o n a l e ~ S u p e ́ r i e u r e ~ d e ~ C h i m i e ~ d e ~ L i l l e, ~ A v e n u e ~ M e n d e l e i e v, ~} 59652$ Villeneuve-d'Ascq,

France 


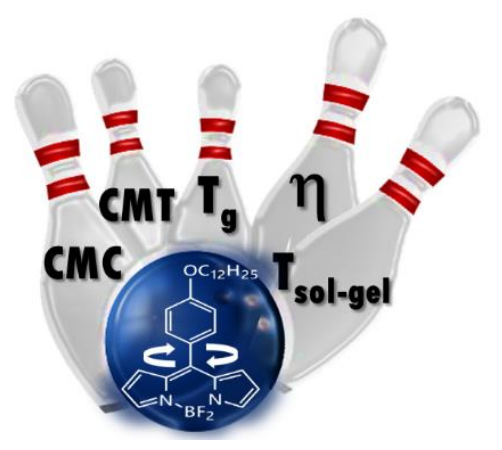

For Table of Contents use only

ABSTRACT: Comprehensive characterization of self-assembled materials is crucial for plethora of different applications, however, remains tedious multi-instrument process. To tackle this issue, fluorescence properties of a boron-dipyrromethene derivative containing lipophilic tail (BODIPYC12) were employed to extensively characterize two self-assembling polymers (Pluronics P123 and F127). We demonstrate that at least five different parameters, i.e. critical micelle concentration, critical micelle temperature, internal microviscosity within the micelles, micelle core glass transition temperature, and the sol-gel transition temperature are possible to obtain by means of steady-state and time-resolved fluorescence spectroscopy utilizing a single BODIPYC12 sensor. This represents a unified methodology for multiparameter characterization of supramolecular polymeric structures and their self-assembly processes. The approach is a compelling non-destructive alternative to the conventional use of several different techniques for the same analytical purposes.

\section{INTRODUCTION}

Self-assembly is a unique property of amphiphilic polymers and is widely used in catalysis, chemical separation, drug delivery systems, and tissue engineering technologies. ${ }^{1-7}$ However, the polymer self-assembly process as well as properties of the colloids formed have to be thoroughly characterized and subsequently optimized to achieve the best possible performance for the 
application needed. In this regard, such characteristics as critical concentrations and temperatures, as well as phase transitions and mobilities are of paramount importance. These properties are usually studied with distinct methods, each requiring a separate optimization step. All in all, it makes the scrutiny of polymeric self-assembly tedious and time-consuming. Thus, a technique that would address several characterization issues at once is highly desired.

Molecular rotors are well known to sense variations in the viscosity of their immediate microenvironment via changes in their fluorescent properties. ${ }^{8}$ As both the fluorescence intensity and the lifetime of the rotors strongly depend on viscosity of their surroundings, a large variety of fluorescence-based techniques is available. Notably, lifetime-based viscosity measurements have a distinctive value as they avoid uncertainty due to unknown local probe concentration in such complex heterogeneous samples as polymeric self-assemblies.

During the last decade, Kuimova and coworkers have developed a novel promising class of fluorescent molecular rotors based on 4,4'-difluoro-4bora-3a,4a-diaza-s-indacene, also known as BODIPY, meso-substituted with para-alkylphenyl moiety (Fig. 1). ${ }^{9}$

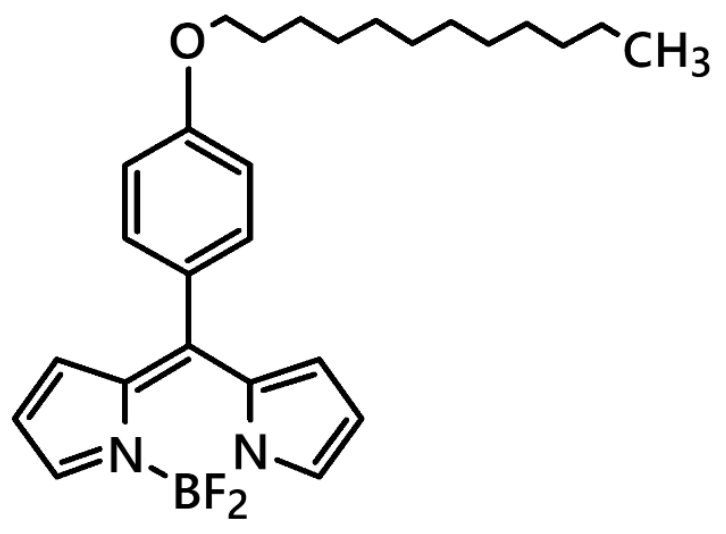

Figure. 1. Chemical structure of the BODIPY-C12 (BPC12). 
These BODIPY based rotors are designed to sense viscosity in hydrophobic environments and have been reported to be suitable for a vast variety of complex heterogeneous systems, such as model lipid bilayers, ${ }^{10,11}$ cells, ${ }^{12-16}$ aerosols,${ }^{17}$ and gelling agents. ${ }^{18}$

In this study, we employed a viscosity sensitive BODIPY derivative with an alkyl chain of twelve carbon atoms BODIPY-C12 (BPC12) (Fig. 1) and demonstrated its great potential to characterize self-assembling polymers. Specifically, we showed that the probe can be used not only for the viscosity sensing but also serves as a multifunctional tool for studying a larger set of different properties of self-assembling materials.

Pluronics represent triblock copolymers of A-B-A structure containing hydrophobic poly(propylene oxide), PPO, as a central block (B) surrounded by two hydrophilic blocks (A) of poly(ethylene oxide), PEO, at the both sides of PPO (Scheme 1). ${ }^{4,19}$ Being relatively nontoxic FDA-approved polymeric surfactants, the Pluronics have found multiple applications in e.g. drug delivery. ${ }^{20}$ Due to their amphiphilic nature, the copolymers self-assemble in aqueous solutions at concentrations above critical micelle concentration (CMC) and form micellar structures. The micelles have a hydrophobic core made of PPO blocks and a hydrophilic shell of PEO chains screening the core part from a contact with aqueous surroundings. The hydrophobic core can incorporate various therapeutic agents, thereby increasing their solubility and stability, while the hydrophilic shell maintains good dispersion stability and allows the use of the micelles for drug delivery in the human body. ${ }^{4}$ 
Scheme 1. Pluronic triblock copolymers P123 and F127.

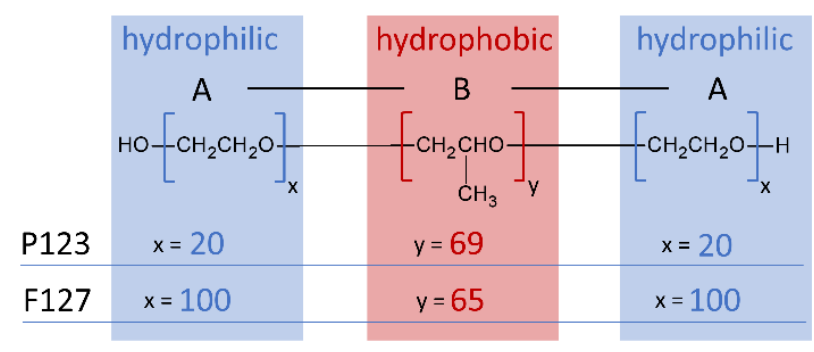

In this work, we particularly focus on two Pluronics (P123 and F127) containing approximately the same number of hydrophobic PPO units, i.e. 69 and 65, respectively, but different numbers of hydrophilic PEO blocks, viz. 39 for P123 and 200 for F127 (Scheme 1). ${ }^{21}$ As their potential as micellar carriers for drug and gene delivery has been widely recognized, multiple studies on their characterization and applications are available..$^{4,20,22-27}$

Micelles encounter different environmental changes upon administration to human body, such as inevitable dilution, varying $\mathrm{pH}$ and salt concentrations, interaction with proteins and cells. Therefore, careful characterization of micelle stability in different conditions is needed. ${ }^{28}$ The concentration above which materials spontaneously form micelles in a solution, called critical micelle concentration, $\mathrm{CMC}$, is used to characterize the thermodynamic stability of micelles. CMC is quantified by many different techniques including fluorometry that is of particular interest regarding current work. ${ }^{20,28}$ The micelle formation is also a temperature dependent process, e.g. CMC dramatically increases upon cooling and, on the other hand, decreases upon temperature elevation. The temperature above which the polymer at particular concentration forms micelles is determined as critical micelle temperature (CMT) and is frequently utilized for the characterization of micellar systems. ${ }^{29,30}$ Micelle core mobility is another important feature, denoting the temperature where the hydrophobic core chains become more flexible. The increased mobility of the micelle core due to transition of the core polymers from gel or crystalline state to liquid/molten 
one may in turn lead to an impulsive burst drug release at physiological temperatures. ${ }^{31}$ There seems no yet established term in the community to describe the transition that led to a diversity of the phenomenon descriptions. In the study of Evans et al. the temperature at which the micelle core mobility/elasticity increases is called glass transition temperature in micelles (Tg); phase transition from micelles micelles ; in study ,Hence, micelle core $T_{g}$ should be carefully controlled in drug delivery system design. transition temperature $T_{g}$

Pluronics are also known to undergo sol-gel transition at a critical temperature called the gelation temperature, $T_{\text {sol-gel. }}$. The transition is described as a thermoreversible transformation of a micellar solution (sol) into an entangled network structure (gel). The polymer solutions having gelation temperatures between ambient and physiological temperatures are of particular interest for biomedical applications. Being soluble at room temperature they form a gel inside the human body upon the temperature increase after the injection and can be used e.g. as drug depots with sustained release in drug delivery. ${ }^{32-34}$

Here we demonstrate that a single molecular probe BPC12 can be used for the comprehensive characterization of amphiphilic polymers. The fluorescent properties of the selected molecular rotor have been shown to be independent of the temperature as such in the range from 5 to $60{ }^{\circ} \mathrm{C}$, but they only reflect environmental changes ${ }^{35}$ which is an additional benefit for studying thermosensitive systems. Besides micelle viscosity, several important parameters, such as CMC, CMT, micelle core $T_{g}$ and gelation temperature are determined by dint of only fluorescence spectroscopy.

\section{MATERIALS AND METHODS}

\section{Materials}


Pluronic polymers F127 (F127, Mn: 12600 Da, 70\%w/w PEO) and P123 (P123 Mn: 5800 Da, $30 \% \mathrm{w} / \mathrm{w}$ PEO) as well as 1,6-diphenyl-1,3,5-hexatriene (DPH) were purchased from SigmaAldrich (St. Louis, MO). 2-(4-Dimethylamino)styryl)-1-methylpyridinium iodide (Daspmi) was purchased from Molecular Probes Inc., Life Technologies. All the chemicals were used without further purification. BPC12 was synthesized in our group according to literature methods. ${ }^{36}$ Gibco $^{\text {TM }}$ Dulbecco's phosphate-buffered saline (DPBS) pH 7.25 was purchased from Thermo Fisher Scientific (Massachusetts, USA).

\section{Methods}

Steady-state fluorescence. The fluorescence spectra of the sample solutions were obtained using a Fluorolog-3 spectrofluorometer (HORIBA Jobin Yvon, UK) and a FLS-1000 spectrofluorometer (Edinburgh Instruments, UK) both equipped with a thermocontrolled cuvette holder. The excitation wavelengths were $490 \mathrm{~nm}$ for BPC12, $460 \mathrm{~nm}$ for Daspmi, and $356 \mathrm{~nm}$ for DPH.

Time-resolved fluorescence. Fluorescence intensity decay curves were measured using timecorrelated single photon counting (TCSPC) system (PicoQuant, GmBH) containing PicoHarp 300 controller and a PDL 800-B driver. LDH-P-C-485 was used to excite the sample at $483 \mathrm{~nm}$ with the time resolution of $\sim 100 \mathrm{ps}$. Detection system was the microchannel plate photomultiplier tube (Hamamatsu R2809U). Cutoff filter of transmission $>490 \mathrm{~nm}$ was applied to reduce an impact of the excitation light scattering. Fluorescence decays were monitored at $520 \mathrm{~nm}$ for BPC12 and at $560 \mathrm{~nm}$ for Daspmi. Instrumental response function (IRF) was measured separately at monitoring wavelength $483 \mathrm{~nm}$ and used for deconvolution analysis of the fluorescence decays followed by their fitting by sum of exponents (Eq. 1)

$I(t, \lambda)=\sum_{i} a_{i} e^{-t / \tau_{f i}}$

where $\tau_{f i}$ is the fluorescence lifetime and $a_{i}$ is the amplitude (pre-exponential factor). 
Critical micelle concentration was determined at $22{ }^{\circ} \mathrm{C}$ and $37^{\circ} \mathrm{C}$ by steady-state fluorescence spectroscopy using BPC12 derivative as fluorescent probe. Another probe DPH commonly used for CMC determination was employed as a control to validate the CMC values obtained by means of BPC12. Fluorescence intensities were monitored at corresponding fluorescence maxima of the used probes: $517 \mathrm{~nm}$ for BPC12 (Fig. SI1a) and $429 \mathrm{~nm}$ for DPH (Fig. SI1b).

Initial stock solutions of BPC12 (1.32 mM), DPH $(1.48 \mathrm{mM})$ and both Pluronics $(1 \mathrm{mM})$ were prepared in chloroform. The fluorescent probes in chloroform were added to DPBS buffer yielding final concentrations of $1.32 \mu \mathrm{M}$ for BPC12 and $1.48 \mu \mathrm{M}$ for DPH. Traces of chloroform were removed using rotary evaporator for 5 minutes at the pressures of $50 \mathrm{mBar}\left(22^{\circ} \mathrm{C}\right)$ and $150 \mathrm{mBar}$ $\left(37^{\circ} \mathrm{C}\right)$. The evaporation conditions were selected to assure complete chloroform elimination and simultaneously to avoid the evaporation of water. Increasing amounts of Pluronics were added consecutively to the sample followed by the evaporation of chloroform. The samples were thoroughly mixed before the fluorescence measurements to facilitate a uniform distribution of the dye and copolymer in the measurement solution. The protocol of consecutive evaporation and mixing was repeated after each polymer addition to keep the volume of the measured sample as well as concentration of the fluorescent probe constant. Final volume losses after full series of measurements were always below $10 \%$ and did not interfere the obtained data analysis and interpretation.

Critical micelle temperature was measured by monitoring fluorescence intensity of BPC12 in two different concentrations of each polymer. The micellar solutions were prepared in weight/volume$\%$ by taking corresponding mass of P123 paste and F127 flakes to make 3\%w/v (5.2 mM) and $10 \% \mathrm{w} / \mathrm{v}(17 \mathrm{mM})$ solutions of $\mathrm{P} 123$, and $6 \% \mathrm{w} / \mathrm{v}(4.8 \mathrm{mM})$ and $10 \% \mathrm{w} / \mathrm{v}(7.9 \mathrm{mM})$ solutions of F127, respectively. The solution preparation was rather easy for F127 as it was a solid at room 
temperature. However, P123 is a paste at room temperature and was measured by volume using known P123 paste density of $1.0189 \mathrm{~g} / \mathrm{ml}$. The corresponding amounts of F127 flakes and P123 paste were added directly to DPBS and the mixture was at once supplemented with BPC12 in chloroform. The mixture was left mixing overnight under magnetic stirring to ensure the complete distribution of the polymer in the solutions and chloroform evaporation. The polymer micellar solutions (sols) for all the following experiments were prepared using the same protocol. Temperature ramp experiments with the above micellar solutions of P123 and F127 containing 6.6 $\mu \mathrm{M} \mathrm{BPC} 12$ were performed in the temperature range $4-25^{\circ} \mathrm{C}$ with about $1{ }^{\circ} \mathrm{C}$ steps.

Viscosity in micelles. Viscosities were correlated to fluorescence lifetimes using the modified Förster-Hoffman equation in logarithmic form (Eq. 2)

$\log \tau_{f}=\log \frac{z}{k_{r}}+\alpha \log \eta$

where $\tau_{f}$ - fluorescence lifetime of BPC12 in the solution of a given viscosity $\eta$, and $z$ and $\alpha$ are constants. Thus, plot of $\log \tau_{f}$ as a function of $\log \eta$ serves as calibration curve for BPC12 behavior depending on the environmental viscosity. ${ }^{37}$

Two series of seven methanol/glycerol mixtures of different viscosities at concentrations of glycerol between $0 \%$ and $100 \%$ (vol/vol) were prepared as a calibration set. Viscosities $(\eta)$ of each binary mixture were measured at $22{ }^{\circ} \mathrm{C}\left(1 \mathrm{st}\right.$ series) and at $37^{\circ} \mathrm{C}$ (2nd series) using HAAKETM Viscotester ${ }^{\mathrm{TM}}$ iQ (Thermo Fisher Scientific, Germany). Each methanol/glycerol mixture was used to dissolve $1.8 \mu \mathrm{M}$ of BPC12 and the corresponding fluorescence intensity decays were recorded in quartz cuvettes using the TCSPC system (PicoQuant, GmBH) described above (Fig. SI2a, c). Linear calibration plots of the solvent viscosity versus fluorescence lifetime at $22{ }^{\circ} \mathrm{C}$ and $37{ }^{\circ} \mathrm{C}$ were obtained in double logarithmic scale (Fig. SI2b, d). 
Micellar solutions of F127 and P123 for viscosity measurements were prepared in DPBS buffer solution at $5 \mathrm{mM}$ polymer concentration $(2.9 \% \mathrm{w} / \mathrm{v}$ for P123 and $6.3 \% \mathrm{w} / \mathrm{v}$ for F127) that significantly exceeded the CMC values of both polymers. Three different concentrations of BPC12 $(1,5$, and $10 \mu \mathrm{M})$ were tested at $22{ }^{\circ} \mathrm{C}$ to assure that the concentration quenching of BPC12 emission does not take place to provide reliable viscosity measurements. The quenching would be seen as a shortening of the observed excited state lifetime. ${ }^{37}$ Identical fluorescence decays for all the tested concentrations with the same lifetime values (Fig. SI3a, b) confirmed the absence of the quenching. Therefore, the highest dye concentration was selected for the viscosity measurements at $37^{\circ} \mathrm{C}$ to provide better signal intensity.

Glass transition temperature in micelles or micelle core $\boldsymbol{T}_{g}$ was obtained by time-resolved fluorescence measurements of BPC12 in micellar solutions. The micellar solutions of P123 and F127 in DPBS at $5 \mathrm{mM}$ polymer concentration supplemented by $10 \mu \mathrm{M}$ of BPC12 were measured at different temperatures in the range of $20-46^{\circ} \mathrm{C}$ and $20-58{ }^{\circ} \mathrm{C}$, respectively, with $2{ }^{\circ} \mathrm{C}$ temperature steps.

Size determination. Dynamic light scattering measurements were performed at $22{ }^{\circ} \mathrm{C}$ and $37^{\circ} \mathrm{C}$ using Zetasizer Nano ZS (Malvern Panalytical, UK) to yield information about micelle size. Micellar solutions of P123 and F127 for DLS experiments were prepared in DPBS at $5 \mathrm{mM}$ polymer concentration. The samples were incubated at $22{ }^{\circ} \mathrm{C}$ or $37^{\circ} \mathrm{C}$ on a heating plate for 15 minutes before the measurements to reduce temperature equilibration time inside DLS sample chamber.

Gelation temperature ( $\left.\boldsymbol{T}_{\text {sol-gel }}\right)$ was determined by steady- state and time-resolved fluorescence of BPC12 and Daspmi to describe environmental changes in both hydrophobic and hydrophilic domains of the system upon gelation. $30 \% \mathrm{w} / \mathrm{v}(52 \mathrm{mM})$ solution of P123 and 20\% w/v (16 mM) 
solution of F127 were prepared in DPBS for the sol-gel transition experiments. BPC12 was added at concentration 1.1 $\mu \mathrm{M}$. Fluorescence intensities were monitored at $517 \mathrm{~nm}$ for BPC12 and at 595 $\mathrm{nm}$ for Daspmi. Fluorescence decays of BPC12 and Daspmi were measured at detection wavelength $520 \mathrm{~nm}$ and $560 \mathrm{~nm}$, respectively, upon heating from 8 to $25{ }^{\circ} \mathrm{C}$ for $\mathrm{F} 127$ and from 6 to $25{ }^{\circ} \mathrm{C}$ for P123 and subsequent cooling with temperature steps of $1-2{ }^{\circ} \mathrm{C}$. The sample temperature was equilibrated for 20 minutes before each measurement and between the cycles of heating and cooling. The sol and gel states were visually confirmed, and the $T_{\text {sol-gel }}$ was estimated by tilting the cuvette containing the samples at several temperatures of the heating/cooling cycles.

\section{RESULTS AND DISCUSSION}

\section{Critical micelle concentration}

The micelle formation of Pluronics in aqueous solutions is a concentration- and temperaturedependent process. Considering micelles as a potential drug delivery system, one should evaluate their stability upon dilution in body liquids and at human body temperatures. ${ }^{28}$ The $\mathrm{CMC}$ value serves as a parameter characterizing the micelle stability at a given temperature, i.e. the lowest concentration of the Pluronic above which the micelles are stable. Therefore, the CMC values for the polymers of interest were measured at both $37{ }^{\circ} \mathrm{C}$ and $22{ }^{\circ} \mathrm{C}$ room temperature (RT) by steadystate fluorescence spectroscopy.

Dye solubilization is a well known technique for the determination of CMC. ${ }^{38,39}$ In our work the environmental sensitivity of fluorescence of hydrophobic molecular rotor BPC12 was employed for the first time to determine the CMC of Pluronics P123 and F127. Upon micelle formation, the microenvironment around BPC12 molecules changed from hydrophilic to hydrophobic when the dye was incorporated (solubilized) inside the hydrophobic core of the micelles. The environmental change is known to lead to a significant increase in BPC12 fluorescence intensity and lifetime. ${ }^{9}$ 
Such a dramatic difference in BPC12 fluorescence in buffer and micellar surroundings allows us to use the dye solubilization by micelles as a contrast mechanism to determine CMC. Plots of BPC12 fluorescence intensity change upon increasing the concentration of Pluronics are presented in Fig. 2a, b.
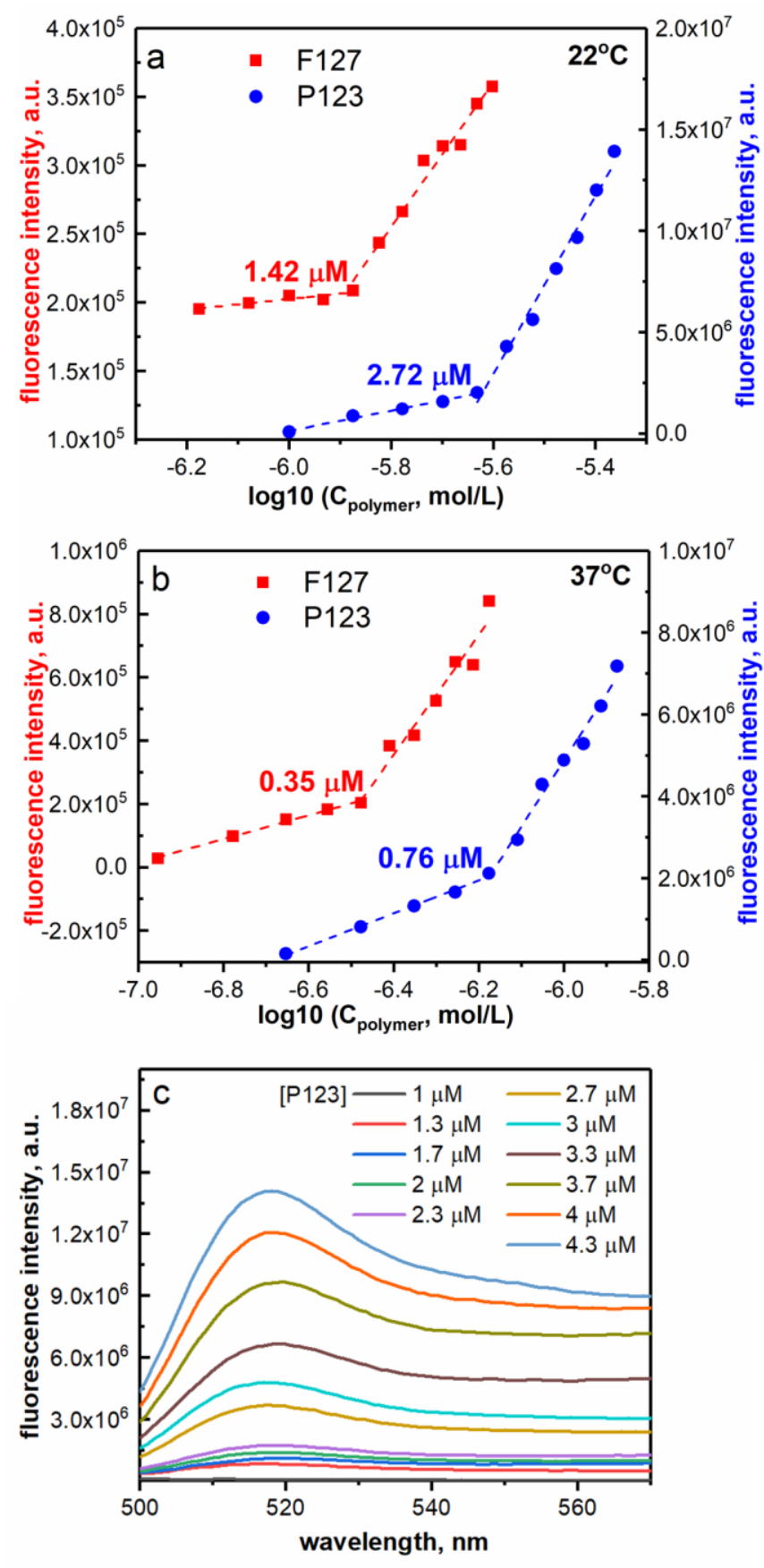

corrected 
Figure 2. Fluorescence intensity of $1.32 \mu \mathrm{M}$ BPC12 in the presence of different concentrations of the polymers P123 (blue circles) and F127 (red squares) monitored at $517 \mathrm{~nm}\left(\lambda_{\mathrm{ex}}=490 \mathrm{~nm}\right)$. Plots for the determination of $\mathrm{CMC}$ for the both polymers at $22{ }^{\circ} \mathrm{C}$ (a) and $37^{\circ} \mathrm{C}$ (b). (c) Fluorescence spectra of BPC12 upon titration by increasing concentrations of P123 at $22{ }^{\circ} \mathrm{C}$.

To validate BPC12 solubilization method described above, control experiments at the same temperature conditions and using the same sample preparation protocols were performed utilizing a hydrophobic dye DPH conventionally used in fluorescent CMC determination technique (Fig. SI4a, b). ${ }^{38,39}$ The CMC for both Pluronic block copolymers determined using BPC12 and DPH at two different temperatures are presented in Table 1. The results obtained with the both dyes are in good agreement (e.g. $2.72 \mu \mathrm{M}$ vs. $3.04 \mu \mathrm{M}$ for $\mathrm{P} 123$ at $22{ }^{\circ} \mathrm{C}$ ), confirming the validity of the BPC12-based approach. CMC values for P123 are about 2 times higher than for F127 (e.g. $2.72 \mu \mathrm{M}$ vs. $1.42 \mu \mathrm{M}$ at $22^{\circ} \mathrm{C}$ ) due to a bigger contribution of hydrophilic units in $\mathrm{F} 127$ that facilitate the screening of the hydrophobic core from water. ${ }^{26}$ The values at $37{ }^{\circ} \mathrm{C}$ are expectedly about 4 times lower compared to those at $22{ }^{\circ} \mathrm{C}$ which is explained by the changes in the micelle polarity resulting in the dehydration and increase in the aggregation number upon temperature rise. ${ }^{40}$ The CMC of F127 and P123 published earlier by Kabanov et. al. ${ }^{26}$ (2.8 and $4.4 \mu \mathrm{M}$ at $\left.37{ }^{\circ} \mathrm{C}\right)$ are higher than those obtained in our work $\left(0.4\right.$ and $0.8 \mu \mathrm{M}$ at $\left.37^{\circ} \mathrm{C}\right)$. This is due to the different media used in these studies. We performed the experiments in DPBS, while bidistilled water was used in the article above. Similarly to temperature effect, addition of salts also leads to the dehydration of the hydrophilic micelle corona (salting out effect) and hence decreases CMC. ${ }^{41,42}$

\section{Critical micelle temperature}

Micellization is a thermoreversible process, and the CMT is determined as the lowest possible temperature at which the micelles are stable in the solution at a given surfactant concentration. To 
pinpoint the CMT values for both studied polymers we monitored steady-state fluorescence intensity of $\mathrm{BPC} 12$ at different temperatures upon heating and cooling. The same dye solubilization principle as in CMC experiments was utilized to obtain CMTs.

Plots of the change in BPC12 fluorescence intensity monitored at $517 \mathrm{~nm}$ upon heating and cooling in 3\%w/v P123 and 10\%w/v F127 are presented in Fig. 3a, b. Graphs for the other concentrations of the Pluronics (10\% P123 and 6\% F127) are shown in Fig. SI5a, b. The temperature where the fluorescence intensity ceased to increase during the heating cycle was attributed to a complete micellization of the solution. The obtained CMTs are $15{ }^{\circ} \mathrm{C}$ and $8{ }^{\circ} \mathrm{C}$ for $3 \%$ and $10 \% \mathrm{P} 123$, and $21{ }^{\circ} \mathrm{C}$ and $17{ }^{\circ} \mathrm{C}$ for $6 \%$ and $10 \% \mathrm{~F} 127$ (Table 1). The values are in line with those reported earlier for the polymers in literature using different methods, e. g. NMR, static light scattering and fluorescence anisotropy techniques. ${ }^{29,30,43,44}$ Moreover, the CMT results also expectedly show that the micellization temperature decreases with the polymer concentration increase and vice versa. ${ }^{29}$ 

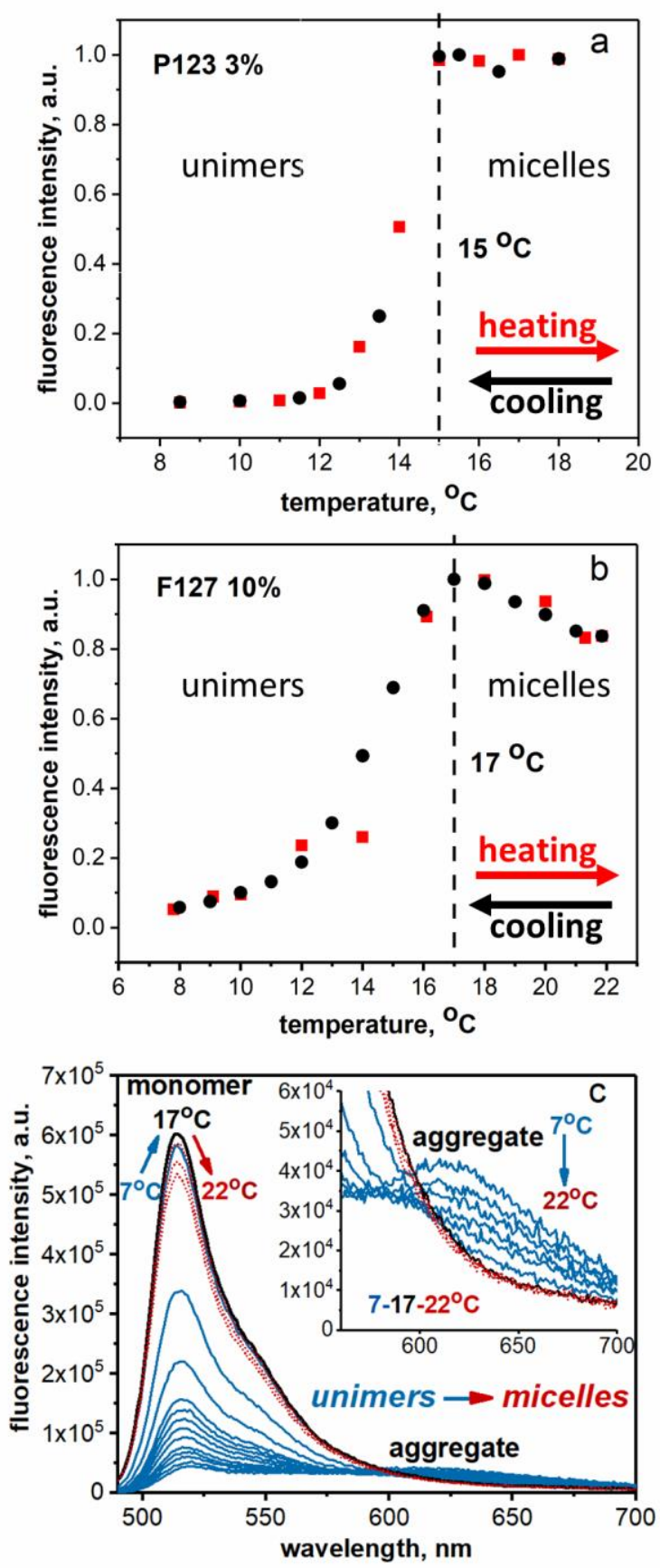

corrected

Figure 3. Steady-state fluorescence intensity of BPC12 monitored at $517 \mathrm{~nm}\left(\lambda_{\mathrm{ex}}=490 \mathrm{~nm}\right)$ as a function of temperature in 3\% solution of P123 (a) and 10\% solution of F127 (b) in DPBS. Heating cycle - red squares, cooling cycle - black circles. Plots for the determination of CMTs. (c) Fluorescence spectra of BPC12 in 10\% solution ofF127 corresponding to the plot (b) where arrows 
show spectral changes upon heating (BPC12 monomer peak at ca. $517 \mathrm{~nm}$ and its aggregate - ca. $610 \mathrm{~nm})$.

Table 1. Characteristics of self-assembling polymers P123 and F127 determined by means of molecular rotor BPC12.

$\mathrm{CMC}, \mu \mathrm{M}$

\begin{tabular}{|l|c|c|}
\hline Polymer & $22^{\circ} \mathrm{C}$ & $37^{\circ} \mathrm{C}$ \\
\hline P123 & $2.7 \pm 0.2(3)^{*}$ & $0.76 \pm 0.10(3)$ \\
\hline P123/DPH control & $3.04 \pm 0.05(2)$ & $0.65(1)$ \\
\hline F127 & $1.42 \pm 0.16(2)$ & $0.348 \pm 0.005(2)$ \\
\hline \multicolumn{2}{|c|}{ CMT,${ }^{\circ} \mathrm{C}$} \\
\hline
\end{tabular}

\begin{tabular}{|l|c|}
\hline P123 $(3 \% \mathrm{w} / \mathrm{v})$ & $15.0 \pm 0.5(2)$ \\
\hline P123 $(10 \% \mathrm{w} / \mathrm{v})$ & $8.0(1)$ \\
\hline F127 $(6 \% \mathrm{w} / \mathrm{v})$ & $21.0(1)$ \\
\hline F127 $(10 \% \mathrm{w} / \mathrm{v})$ & $17.0 \pm 0.5(2)$ \\
\hline
\end{tabular}

\begin{tabular}{|l|c|}
\hline P123 $(5 \mathrm{mM})$ & $34.0 \pm 0.5(3)$ \\
\hline F127 $(5 \mathrm{mM})$ & $39.0 \pm 0.5(3)$ \\
\hline
\end{tabular}

Viscosity of micelles, cP

\begin{tabular}{|l|c|c|}
\hline & $22^{\circ} \mathrm{C}$ & $37^{\circ} \mathrm{C}$ \\
\hline P123 (5 mM) & $239 \pm 9(4)$ & $60 \pm 6(3)$ \\
\hline F127 (5 mM) & $167 \pm 10(3)$ & $40 \pm 6(3)$ \\
\hline
\end{tabular}

\begin{tabular}{|l|c|}
\hline P123 $(30 \% \mathrm{w} / \mathrm{v})$ & $13.0 \pm 1.0(2)$ \\
\hline F127 $(20 \% \mathrm{w} / \mathrm{v})$ & $17.0 \pm 1.0(2)$ \\
\hline
\end{tabular}

*Number of replicates for each experiment is given in parentheses 
After CMT the fluorescence intensity of F127 slowly starts to decrease (Fig. 3b and Fig. SI5b) in contrast to P123 where it stays constant even within $3-4{ }^{\circ} \mathrm{C}$ over the CMT (Fig. 3a and Fig. SI5a). The behavior is explained by the difference in the hydrophilic/hydrophobic balance of the two polymers leading to their different micelle structure. P123 has smaller hydrophilic part (40 PEO) compared to F127 (200 PEO). Hence, more molecules of P123 is needed to have enough of hydrophilic units for the shell to screen hydrophobic core from aqueous medium and form stable micelles. This is seen by higher CMC for P123 than for F127 as shown in the previous section, and 2.5 times higher aggregation number 107 was reported for P123 versus that one 42 for F127 in water at $30{ }^{\circ} \mathrm{C} .{ }^{45}$ Having less polymer molecules but similar size (Table SI1) F127 micelles are less densely packed and have less hydrophobic units in the core part. While P123 micelles are more compact and have more hydrophobic units. The densities of the micelles are in line with the internal viscosities determined in the next section, $239 \mathrm{cP}$ for $\mathrm{P} 123$ versus $167 \mathrm{cP}$ for $\mathrm{F} 127$ at $22{ }^{\circ} \mathrm{C}$ (Table 1). Thus, further temperature elevation over CMT affects mobility of the hydrophobic core of loosely packed F127 micelles in a greater extent and faster than in case of more compact P123 micelles. However, the higher temperatures finally lead to viscosity decrease and probe fluorescence decrease in P123 micelles similarly to F127 as seen in the following sections of $T_{g}$ and $T_{\text {sol-gel }}$ determination.

The $\mathrm{BPC} 12$ is known to form aggregates in hydrophilic media and the formation of the aggregates is manifested by the appearance of a new emission band at about $610 \mathrm{~nm}$ (Fig. 3c). ${ }^{35}$ Upon micelle formation the molecular rotor solubilizes, and the aggregates disintegrate into monomers with the emission band at $517 \mathrm{~nm}$ as shown by arrows in Fig. $3 \mathrm{c}$ and its inset. Thus, the fluorescence spectrum shape of BPC12 is another indicative and a solid confirmation of stable micelle formation. 
Fluorescence decays of $10 \% \mathrm{w} / \mathrm{v}$ F127 were recorded to check whether BPC12 lifetime could be an indicator of the unimer to micelle transition and allow more accurate determination of the CMT (Fig. SI6). The time-resolved measurements gave micellization temperature similar to that obtained in the steady-state experiments. Fluorescence decays of the dye in unimer solution appeared to show a multiexponential character at the temperatures below CMT (Fig. SI6, black and blue curves), due to BPC12 aggregation in aqueous solution. ${ }^{35}$ While upon heating the polymer over its micellization temperature the kinetics became monoexponential (Fig. SI6, green and red curves) indicating the micelle formation and the solubilization of the molecular rotor.

\section{Micelle characterization}

Micelle formation at $5 \mathrm{mM}$ polymer concentration exceeding the measured $\mathrm{CMC}$ was proved by DLS measurements (Table SI1). The Pluronics were shown to form micelles with comparable sizes, $24 \mathrm{~nm}$ for F127 and $22 \mathrm{~nm}$ for P123. Heating the micelles from room temperature to $37^{\circ} \mathrm{C}$ caused a slight decrease in micelle size. Size distribution was narrower for P123 than in case of F127 micelles as concluded from their PDI values.

Kinetic micelle stability of P123 micelles was indirectly followed by TCSPC measurements of BPC12 in the micelles for several days. Lifetime of the dye stayed unchanged for at least 8 days suggesting that the micellar solution was stable for over a week (Fig. SI7).

\section{Viscosity in micelles}

Polymeric micellar solutions are heterogeneous systems where viscosities vary significantly from one micro-domain to another. Thus, local environmental mobility at microscopic level, e. g. in buffer, micelle core, or micelle corona can be rather different. Being designed to measure viscosity in hydrophobic media, ${ }^{9,37}$ in our study BPC12 was incorporated in the hydrophobic micelle core completely and could thus be used to sense the changes in the core viscosity. 
Viscosities in the micelles made of both studied polymers P123 and $\mathrm{F} 127$ at $22^{\circ} \mathrm{C}$ and $37^{\circ} \mathrm{C}$ (Table 1) were determined using corresponding calibration curves (Fig. SI2b, d). Core viscosities of both F127 and P123 micelles at $37{ }^{\circ} \mathrm{C}$ were expectedly about four times lower than the corresponding values at $22{ }^{\circ} \mathrm{C}$ (e.g. $60 \mathrm{cP}$ vs. $239 \mathrm{cP}$ for P123). Interestingly, the viscosity of F127 micelles core turned out to be smaller compared to P123 micelles regardless the measurement temperature suggesting that P123 micelles are more densely packed compared to F127 ones.

\section{Glass transition temperature in micelles $\left(T_{g}\right)$}

Herein we describe a direct non-destructive method to measure micelle core $T_{g}$ in Pluronics based micelles. To the best of our knowledge, this is the first time when the time-resolved fluorescence spectroscopy is used in this application. The phenomenon of micelle core fluidity change was scarcely studied at low polymer concentrations due to lack of available methodology. Differential scanning calorimetry (DSC), the conventional method used for glass transition temperature determination, is difficult to implement for micellar systems. ${ }^{46}$ Moreover, besides a somewhat complicated sample preparation protocol, DSC results depend on many parameters among which the volume of the glass former in the sample and heating/cooling rate are the most critical ones. ${ }^{47}$ The term $T_{g}$ was applied to describe the change in polymeric micelle core mobility following a paper of Evans et al. where authors proposed steady-state fluorescence based technique

to determine $T_{g}$ of micelle core. ${ }^{46}$ Although the steady-state spectroscopy is technically easier than the time-resolved one, it includes an additional step of covalent labelling of the diblock copolymer with a pyrene probe to control probe concentration and ensure reliability of fluorescence intensity data. Another inconvenience of the method presented by Evans and coworkers is that the small contribution of pyrene excimer emission to the general integrated fluorescence intensity should have been accounted for. In our work, the dye sensor is incorporated into the core by a non- 
covalent self-assembly. The TCSPC technique allows the measurement of fluorescence lifetime at a specific wavelength corresponding to the singlet excited state fluorescence. Hence, any potential contribution of the other excited state species is initially excluded. Fluorescence lifetime independence of the probe concentration is another evident benefit of using time-resolved fluorescence spectroscopy. ${ }^{48}$ However, we would like to additionally note that the used term micelle core $\mathrm{Tg}$ differs from a classic understanding of $\mathrm{Tg}$ in bulk polymers. The difference is mediated by the presence of additional interactions between polymers in the presence of aqueous buffer solution namely their self-assembly feature. We do believe that the self-assembly mediated by the solvent presence dramatically affect $\mathrm{Tg}$ of the final micelle core, and the micelle core $\mathrm{Tg}$ cannot be directly compared to dry bulk polymer $\mathrm{Tg}$.

Fluorescence decays of BPC12 in P123 and F127 micelles at different temperatures are presented in Figures $4 \mathrm{a}$ and $4 \mathrm{c}$, respectively. Fluorescence lifetimes were calculated using monoexponential fitting model (Eq. 1) and plotted as a function of temperature (Fig. 4b, d). Clear intersection points between the two linear regions are observed in the obtained dependences at $34{ }^{\circ} \mathrm{C}$ for P123 and $39^{\circ} \mathrm{C}$ for F127. Upon heating over the intersection temperature, the change in fluorescence lifetime becomes shallower meaning that the viscosity dependence on the temperature diminishes. It implies that the hydrophobic micellar core becomes more fluid and the polymer chains attain increased mobility. ${ }^{31}$ Therefore, the intersection temperature is an indicative of glass transition in the core of the studied micelles. Micelle structure becomes more dynamic which may potentially prompt the drug release in drug delivery applications of the Pluronics or may be beneficial in micellar catalysis. Moreover, the obtained intersection temperature does not depend on the polymer concentration and the polymer/dye ratio as shown in Fig. SI8. This 
additionally strengthens the interpretation of the temperature as $T_{g}$ characterizing dynamics of the micellar core rather than bulk $T_{g}$ or any other phase transition known in self-assembling materials.
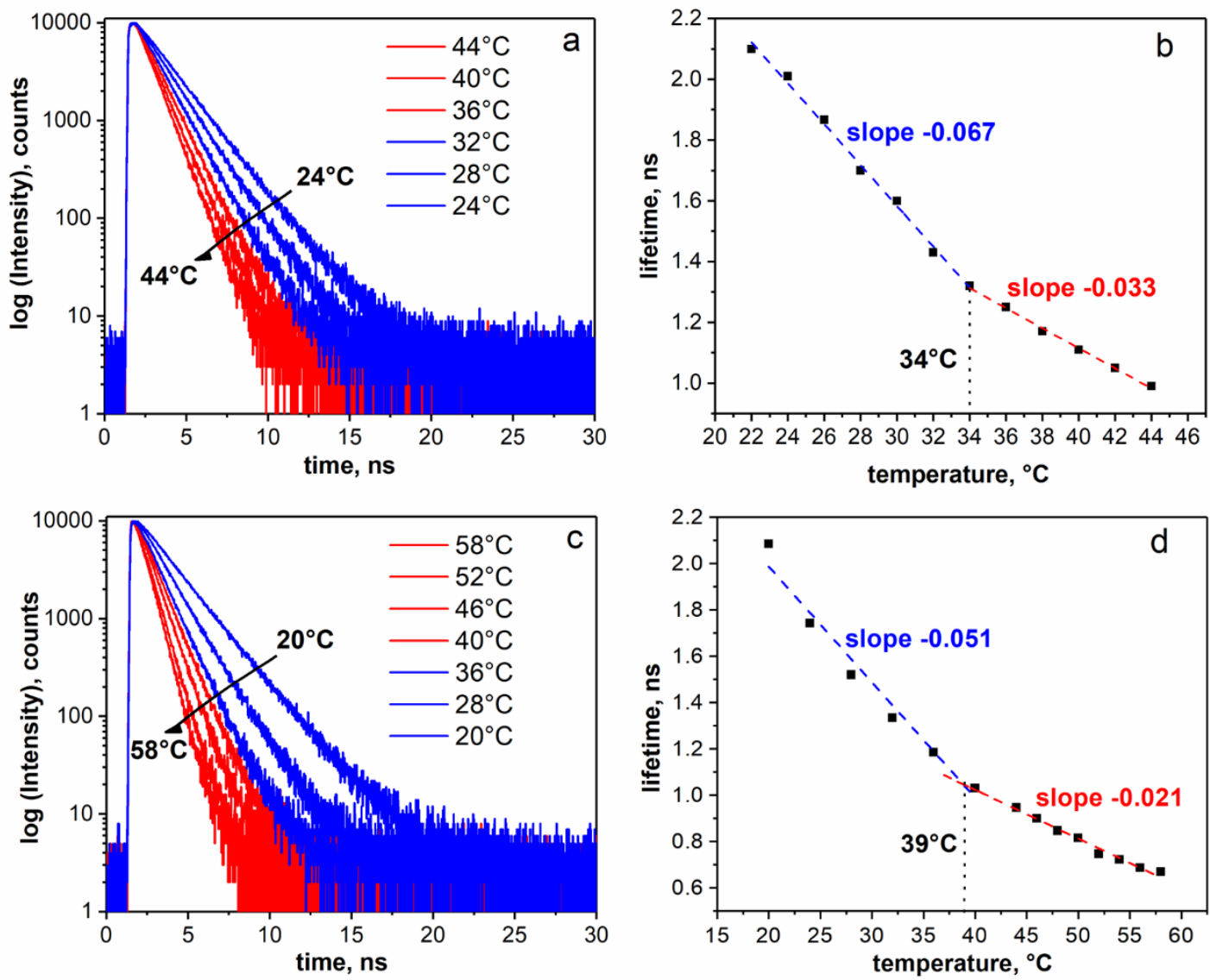

Figure 4. Fluorescence intensity decay curves (a, c) detected at $520 \mathrm{~nm}\left(\lambda_{\mathrm{ex}}=483 \mathrm{~nm}\right)$ and corresponding calculated lifetimes $(\mathrm{b}, \mathrm{d})$ of BPC12 $(10 \mu \mathrm{M})$ in P123 (5 mM) micelles (upper panel $\mathrm{a}, \mathrm{b})$ and F127 (5mM) micelles (lower panel c, d) at different temperatures. The intersection of linear regression fits of the data denotes the $T_{g}$ in the micelle core.

\section{Gelation temperature $\left(T_{\text {sol-gel }}\right)$}

The viscosity sensitive fluorescent properties of BPC12 were used to determine the temperature of gel formation for both P123 and F127 Pluronics. Lifetime-based study of chemically driven gelation using molecular rotors has been recently reported by Hungerford et. al for studying water- 
soluble anionic polysaccharide Gellan gum. ${ }^{18}$ We tested the applicability of both steady-state and time-resolved fluorescence properties of $\mathrm{BPC} 12$ to reveal the gelation in solutions of selfassembling Pluronic triblock copolymers. Upon temperature elevation, the stronger hydrophobic interactions of PPO blocks and a partial dehydration of the PEO shell lead to micelle aggregation and further close packing of the aggregates in a network structure. ${ }^{20,49,50}$ As the gel formation is inevitably accompanied by a restriction of the polymer chain mobility and hence viscosity increase, the BPC12 is capable to sense even minute changes of dye surrounding upon gelation.

To assure polymer gelation we used significantly higher concentrations of the two Pluronics, $30 \% \mathrm{w} / \mathrm{v}(52 \mathrm{mM}) \mathrm{P} 123$ and 20\%w/v (16 mM) F127, compared to those used for micelle formation earlier. At these polymer concentrations visible formation of a hard transparent gel was observed at room temperature, and the solutions were liquid at $4{ }^{\circ} \mathrm{C}$ (Fig. 5a) for the both polymers. Thus, they had $T_{\text {sol-gel }}$ in the same temperature range $4-20{ }^{\circ} \mathrm{C}$ suitable for our equipment.

Steady-state fluorescence intensity of BPC12 monitored at $517 \mathrm{~nm}$ in 30\%w/v P123 follows linear monotonously decreasing trend without any drastic change in the temperature range of interest $4-20^{\circ} \mathrm{C}$ (Fig. SI9). This can be explained by one of the known micelle formation mechanisms when gel is formed via micelle aggregation into larger worm-like structures and then the structures form entangled network. The micelle structure probably stays almost unchanged in the process of gelation. Therefore, BPC12 incorporated in the micelles does not show any pronounced change in fluorescence intensity upon the transition from liquid sol to hard gel. 

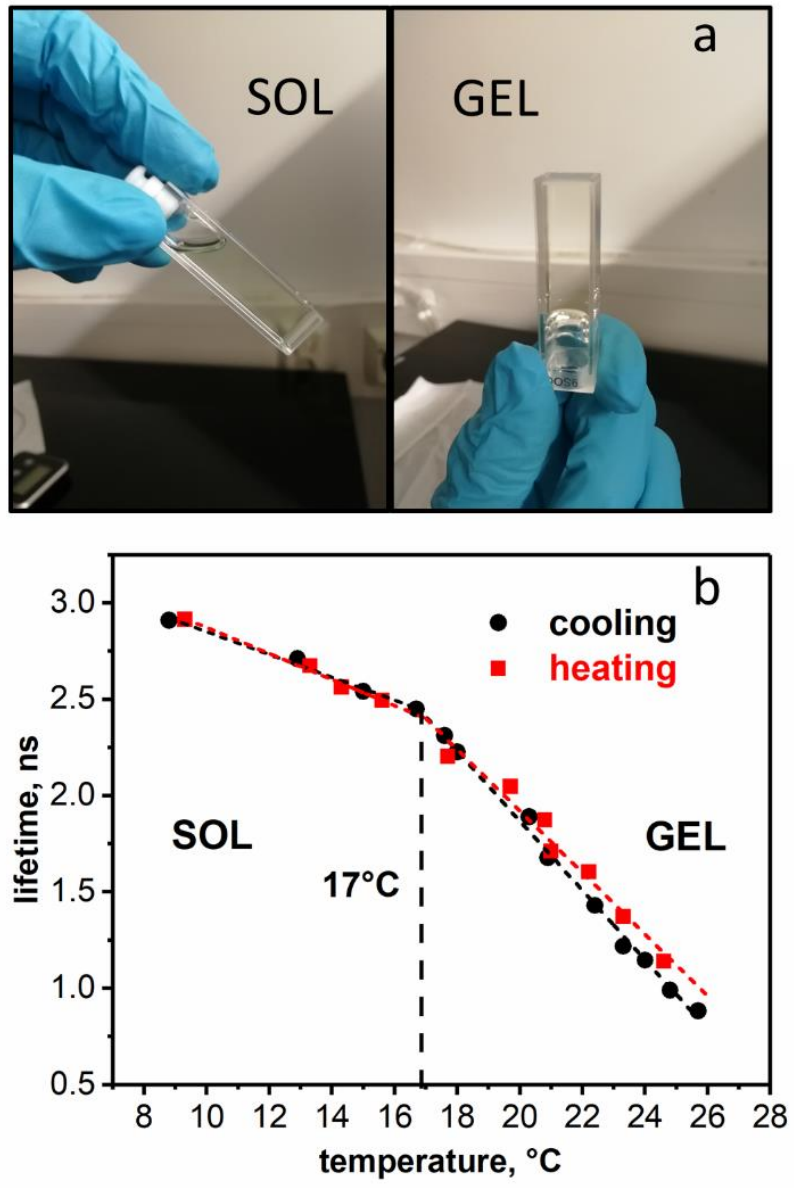

Figure 5. (a) Pictures of $20 \% \mathrm{~F} 127$ at $4{ }^{\circ} \mathrm{C}$ (sol) and at RT (gel). (b) BPC12 fluorescence lifetime monitored at $520 \mathrm{~nm}\left(\lambda_{\mathrm{ex}}=483 \mathrm{~nm}\right)$ in $20 \%$ F127 in DPBS as a function of temperature. Heating cycle - red squares, cooling cycle - black circles.

Fluorescence lifetimes of BPC12 in the same polymeric solutions were measured within the same temperature range. Figure $5 \mathrm{~b}$ shows the lifetimes plotted versus temperature for $20 \% \mathrm{w} / \mathrm{v}$ F127 upon heating (red squares) and consequent cooling (black circles). The resulting lifetime trend shows two linear regions with an intersection point. The temperature at the intersection point was attributed to a complete gelation of the solution. Similar plot for $30 \% \mathrm{P} 123$ is presented in Fig. SI10. The temperatures are $17{ }^{\circ} \mathrm{C}$ for $20 \% \mathrm{w} / \mathrm{v}$ F127 and $13{ }^{\circ} \mathrm{C}$ for $30 \% \mathrm{w} / \mathrm{v}$ P123 (Table 1 ). The obtained temperatures are close to those estimated visually by cuvette tilting method: $19{ }^{\circ} \mathrm{C}$ 
for $20 \% \mathrm{w} / \mathrm{v}$ F127 and $14{ }^{\circ} \mathrm{C}$ for $30 \% \mathrm{w} / \mathrm{v}$ P123. The resulting gelation temperatures are in well agreement with the values reported in literature however slightly lower $\left(2-5^{\circ} \mathrm{C}\right) .{ }^{50-52}$ Similarly to the case of CMC, the lower sol-gel transition temperatures are partly explained by the effect of salts in DPBS buffer as the addition of salting out electrolytes is known to facilitate micellization and gelation processes. ${ }^{41,53,54}$ It should be noted that a direct comparison is difficult because of a diversity of the ways to calculate and prepare a particular polymer concentration as well as a varying accuracy of the temperature measurements in different publications.

Thus, the time-resolved fluorescence measurements are shown to be more sensitive for $T_{\text {sol-gel }}$ determination using $\mathrm{BPC} 12$ probe and are therefore presented in Figure 5b. Although molecular rotors sense only their local microenvironment change, our results show that the gelation process in macroscopic scale of the sample affects the micelle core structure at some extent. And it appeared that the time-resolved fluorescence spectroscopy of BPC12 can detect even these slight micelle structure changes accompanying the sol to gel transition. There are at least two mechanisms of gelation reported for different types of Pluronics, viz. rearrangement from spherical to worm-like micellar structure shown for Pluronics of P type, e.g. P84 and P123, ${ }^{50,55}$ and micelle packing, either via spherical micelle enlargement or via formation of new micelles, leading to shortening of intermicellar distance and consequent micellar network entanglement (cubic structure) proposed for Pluronics of F type, e. g. F108 and F127 $7^{56,57}$. Here we compare P123 and F127 gelling probably via different mechanisms, and we can claim that lifetime measurements are sensitive enough to see macroscopic changes (gelation) via microscopic rearrangements (micellar structure change) taking place upon the gelation process regardless the gelation mechanism.

BPC12 had shown promising though limited sensitivity to sol-get transition likely due to its hydrophobic nature resulting in the dye accumulation and sensing the environment inside the 
micelle. Therefore, we suggested that a hydrophilic rotor could better reflect the viscosity change in the micelle corona or in intermicellar space and, thus, it could better detect the gelation point. We decided to use hydrophilic molecular rotor Daspmi (Fig. SI12) to validate the data obtained using BPC12. According to our data, indeed, the hydrophilic molecular rotor Daspmi has revealed the gelation temperature in both steady-state and time-resolved fluorescence experiments. Similar temperature ramp experiments of $30 \% \mathrm{P} 123$ in the presence of Daspmi gave fluorescence intensity change curve with a maximum at the gelation temperature $14{ }^{\circ} \mathrm{C}$ (Fig. SI11a). Time-resolved data for the same 30\% P123 supplemented with Daspmi yielded a lifetime trend with two intersection points at $13{ }^{\circ} \mathrm{C}$ and $19{ }^{\circ} \mathrm{C}$ (Fig. SI11b). The first temperature agrees with the $T_{\text {sol-gel }}$ determined using BPC12 $\left(13^{\circ} \mathrm{C}\right)\left(\right.$ Fig. SI10) and by cuvette tilting $\left(14^{\circ} \mathrm{C}\right)$ as well as the one obtained in the steady-state fluorescence experiments with Daspmi $\left(14{ }^{\circ} \mathrm{C}\right)$. The second intersection temperature may indicate the end of the gelation process. However, the conclusion needs further studies to be proven as visually the $30 \% \mathrm{P} 123$ represents hard transparent gel already at over $14{ }^{\circ} \mathrm{C}$.

\section{CONCLUSIONS}

Hydrophobic molecular rotor BPC12 can be used for the multiparameter characterization of selfassembling polymers using its strong fluorescence sensitivity to the surrounding environment. For the first time, molecular rotor's steady-state fluorescence spectra have been utilized to determine both the critical micelle concentration and critical micelle temperature. Furthermore, the timeresolved fluorescence spectroscopy of BPC12 offers a novel sensitive, accurate and nondestructive alternative for measuring $T_{g}$ of the polymeric micelle core and simultaneously delivers valuable information about hydrophobic micelle core viscosity. The BPC12 molecule is also useful for studying the thermoreversible sol-gel transitions. Thus, the BODIPY molecular rotor is particularly valuable for determining many important features of self-assembling materials with 
potential for drug delivery applications. We strongly believe that the arsenal of parameters measured using the BODIPY sensor can be expanded and the technique presented in this paper can be generalized for other polymeric materials and applications in different fields of polymerbased nanotechnology. We also suggest that the other molecular rotors may show potential for the fluorescence-based investigation of self-assembling materials.

\section{ASSOCIATED CONTENT}

\section{Supporting Information.}

The Supporting Information is available free of charge at ...

Control experiments of CMC determination by DPH; fluorescence spectra of DPH and BPC12 in micellar solutions; calibration curves for viscosity determination and corresponding fluorescence intensity decays; DLS characterization of the polymeric micelles; steady-state fluorescence CMT experiments at different polymer concentrations and time-resolved fluorescence measurements for CMT determination; time-resolved fluorescence experiments to determine micelle $T_{g}$ at different polymer concentrations; steady-state and time-resolved fluorescence based $T_{\text {sol-gel }}$ experiments using both BPC12 and Daspmi (PDF).

\section{AUTHOR INFORMATION}

\section{Corresponding Authors}

* Ekaterina Lisitsyna - ekaterina.lisitsyna@tuni.fi; Nikita Durandin - nikita.durandin@tuni.fi.

\section{Present Addresses}

${ }^{\dagger}$ Current address: Groupe ECOCERT, Route de Clermont Savès, 32600 L'Isle-Jourdain, France 


\section{Author Contributions}

The work was planned, and the manuscript was written with contributions by all authors.

Experimental design - ND, EL; performance of experiments - EL, CD, PC, ND; synthesis of fluorescent probe $-\mathrm{AE}$; writing of the first manuscript draft - EL; writing of manuscript - EL, ND, AE, EV-L, TL. All authors have given approval to the final version of the manuscript.

\section{Notes}

The authors declare no competing financial interest.

\section{ACKNOWLEDGMENT}

EL, EV-L and TL acknowledge Academy of Finland for funding of the current research (Project Nos. 323669, 311362, 316893). EL also acknowledges Finnish Cultural Foundation.

\section{REFERENCES}

(1) Berezin, I. V.; Martinek, K.; Yatsimirskii, A. K. Physicochemical Foundations of Micellar Catalysis. Russ. Chem. Rev. 1973, 42 (10), 787-802.

(2) Strasters, J. K.; Breyer, E. D.; Rodgers, A. H.; Khaledi, M. G. Simultaneous Optimization of Variables Influencing Selectivity and Elution Strength in Micellar Liquid Chromatography. Effect of Organic Modifier and Micelle Concentration. J. Chromatogr. A 1990, 511, 17-33. https://doi.org/10.1016/S0021-9673(01)93267-4.

(3) Stalikas, C. D. Micelle-Mediated Extraction as a Tool for Separation and Preconcentration in Metal Analysis. Trends Anal. Chem. 2002, 21 (5), 343-355. https://doi.org/10.1016/S0165-9936(02)00502-2.

(4) Batrakova, E. V; Kabanov, A. V. Pluronic Block Copolymers : Evolution of Drug Delivery 
Concept from Inert Nanocarriers to Biological Response Modifiers. J. Control. Release 2008, 130, 98-106. https://doi.org/10.1016/j.jconrel.2008.04.013.

(5) Kataoka, K.; Harada, A.; Nagasaki, Y. Block Copolymer Micelles for Drug Delivery: Design, Characterization and Biological Significance. Adv. Drug Deliv. Rev. 2001, 47, $113-$ 131. https://doi.org/10.1016/j.addr.2012.09.013.

(6) Matricardi, P.; Di Meo, C.; Coviello, T.; Hennink, W. E.; Alhaique, F. Interpenetrating Polymer Networks Polysaccharide Hydrogels for Drug Delivery and Tissue Engineering. Adv. Drug Deliv. Rev. 2013, 65, 1172-1187. https://doi.org/10.1016/j.addr.2013.04.002.

(7) Nicodemus, G. D.; Bryant, S. J. Cell Encapsulation in Biodegradable Hydrogels for Tissue Engineering Applications. Tissue Eng. Part B 2008, 14 (2), 149-165. https://doi.org/10.1089/ten.teb.2007.0332.

(8) Haidekker, M. A.; Nipper, M.; Mustafic, A.; Lichlyter, D.; Dakanali, M.; Theodorakis, E. A. Dyes with Segmental Mobility: Molecular Rotors. In Advanced Fluorescence Reporters in Chemistry and Biology I. Springer Series on Fluorescence (Methods and Applications); Demchenko, A. P., Ed.; Springer: Berlin, Heidelberg, 2010; Vol. 8, pp 267-308. https://doi.org/https://doi.org/10.1007/978-3-642-04702-2_8.

(9) Kuimova, M. K.; Yahioglu, G.; Levitt, J. A.; Suhling, K. Molecular Rotor Measures Viscosity of Live Cells via Fluorescence Lifetime Imaging. J. Am. Chem. Soc. 2008, 130 (21), 6672-6673. https://doi.org/10.1021/ja800570d.

(10) Dent, M. R.; López-Duarte, I.; Dickson, C. J.; Geoghegan, N. D.; Cooper, J. M.; Gould, I. R.; Krams, R.; Bull, J. A.; Brooks, N. J.; Kuimova, M. K. Imaging Phase Separation in 
Model Lipid Membranes through the Use of BODIPY Based Molecular Rotors. Phys. Chem. Chem. Phys. 2015, 17, 18393-18402. https://doi.org/10.1039/c5cp01937k.

(11) Hosny, N. A.; Mohamedi, G.; Rademeyer, P.; Owen, J.; Wu, Y.; Tang, M. X.; Eckersley, R. J.; Stride, E.; Kuimova, M. K. Mapping Microbubble Viscosity Using Fluorescence Lifetime Imaging of Molecular Rotors. Proc. Natl. Acad. Sci. U. S. A. 2013, 110 (23), 92259230. https://doi.org/10.1073/pnas.1301479110.

(12) López-Duarte, I.; Vu, T. T.; Izquierdo, M. A.; Bull, J. A.; Kuimova, M. K. A Molecular Rotor for Measuring Viscosity in Plasma Membranes of Live Cells. Chem. Commun. 2014, 50, 5282-5284. https://doi.org/10.1039/c3cc47530a.

(13) Mika, J. T.; Thompson, A. J.; Dent, M. R.; Brooks, N. J.; Michiels, J.; Hofkens, J.; Kuimova, M. K. Measuring the Viscosity of the Escherichia Coli Plasma Membrane Using Molecular Rotors. Biophys. J. 2016, 111, 1528-1540. https://doi.org/10.1016/j.bpj.2016.08.020.

(14) Sherin, P. S.; López-Duarte, I.; Dent, M. R.; Kubánková, M.; Vyšniauskas, A.; Bull, J. A.; Reshetnikova, E. S.; Klymchenko, A. S.; Tsentalovich, Y. P.; Kuimova, M. K. Visualising the Membrane Viscosity of Porcine Eye Lens Cells Using Molecular Rotors. Chem. Sci. 2017, 8, 3523-3528. https://doi.org/10.1039/c6sc05369f.

(15) Shimolina, L. E.; Izquierdo, M. A.; López-Duarte, I.; Bull, J. A.; Shirmanova, M. V.; Klapshina, L. G.; Zagaynova, E. V.; Kuimova, M. K. Imaging Tumor Microscopic Viscosity in Vivo Using Molecular Rotors. Sci. Rep. 2017. https://doi.org/10.1038/srep41097.

(16) Kubánková, M.; Summers, P. A.; López-Duarte, I.; Kiryushko, D.; Kuimova, M. K. 
Microscopic Viscosity of Neuronal Plasma Membranes Measured Using Fluorescent Molecular Rotors: Effects of Oxidative Stress and Neuroprotection. ACS Appl. Mater. Interfaces 2019, 11, 36307-36315. https://doi.org/10.1021/acsami.9b10426.

(17) Athanasiadis, A.; Fitzgerald, C.; Davidson, N. M.; Giorio, C.; Botchway, S. W.; Ward, A. D.; Kalberer, M.; Pope, F. D.; Kuimova, M. K. Dynamic Viscosity Mapping of the Oxidation of Squalene Aerosol Particles. Phys. Chem. Chem. Phys. 2016, 18, 30385-30393. https://doi.org/10.1039/c6cp05674a.

(18) Hungerford, G.; Allison, A.; Mcloskey, D.; Kuimova, M. K.; Yahioglu, G.; Suhling, K. Monitoring Sol-to-Gel Transitions via Fluorescence Lifetime Determination Using Viscosity Sensitive Fluorescent Probes. J. Phys. Chem. B 2009, 113, 12067-12074.

(19) Schmolka, I. R.; Corp, B. W. A Review of Block Polymer Surfactants. J. Am. Oil Chem. Soc. 1977, 54, 110-116.

(20) Kabanov, A. V; Batrakova, E. V; Alakhov, V. Y. Pluronic ${ }^{\circledR}$ Block Copolymers as Novel Polymer Therapeutics for Drug and Gene Delivery. J. Control. Release 2002, 82, 189-212. https://doi.org/10.1021/acs.jpcb.5b11448.

(21) Batrakova, E.; Lee, S.; Li, S.; Venne, A.; Alakhov, V.; Kabanov, A. Fundamental Relationships between the Composition of Pluronic Block Copolymers and Their Hypersensitization Effect in MDR Cancer Cells. Pharm. Res. 1999, 16 (9), 1373-1379.

(22) Mortensen, K. Structural Studies of Aqueous Solutions of PEO - PPO - PEO Triblock Copolymers, Their Micellar Aggregates and Mesophases; a Small-Angle Neutron Scattering Study. J. Phys. Condens. Matter 1996, 8, 103-124. 
(23) Alexandridis, P.; Hatton, T. A. Poly(Ethylene Oxide)-Poly(Propylene Oxide)-Poly (Ethylene Oxide) Block Copolymer Surfactants in Aqueous Solutions and at Interfaces: Thermodynamics, Structure, Dynamics, and Modeling. Colloids Surfaces A Phisicochemical Eng. Asp. 1995, 96, 1-46.

(24) He, Z.; Alexandridis, P. Micellization Thermodynamics of Pluronic P123 (EO20PO70EO20) Amphiphilic Block Copolymer in Aqueous Ethylammonium Nitrate

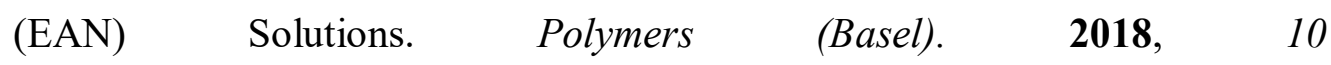
https://doi.org/10.3390/polym10010032.

(25) Pitto-Barry, A.; Barry, N. P. E. Pluronic ${ }^{\circledR}$ Block-Copolymers in Medicine: From Chemical and Biological Versatility to Rationalisation and Clinical Advances. Polym. Chem. 2014, 5 (10), 3291-3297. https://doi.org/10.1039/c4py00039k.

(26) Kabanov, A. V.; Batrakova, E. V.; Miller, D. W. Pluronic ${ }^{\circledR}$ Block Copolymers as Modulators of Drug Efflux Transporter Activity in the Blood-Brain Barrier. Adv. Drug Deliv. Rev. 2003, 55, 151-164. https://doi.org/10.1016/S0169-409X(02)00176-X.

(27) Fares, A. R.; Elmeshad, A. N.; Kassem, M. A. A. Enhancement of Dissolution and Oral Bioavailability of Lacidipine via Pluronic P123/F127 Mixed Polymeric Micelles: Formulation, Optimization Using Central Composite Design and in Vivo Bioavailability

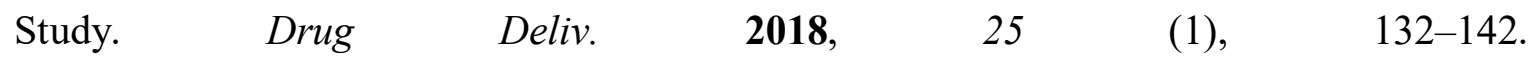
https://doi.org/10.1080/10717544.2017.1419512.

(28) Owen, S. C.; Chan, D. P. Y.; Shoichet, M. S. Polymeric Micelle Stability. Nano Today 2012, 7, 53-65. https://doi.org/10.1016/j.nantod.2012.01.002. 
(29) Alexandridis, P.; Holzwarth, J. F.; Hatton, T. A. A Correlation for the Estimation of Critical Micellization Concentrations and Temperatures of Polyols in Aqueous Solutions. J. Am. Oil Chem. Soc. 1995, 72 (7), 823-826.

(30) Bohorquez, M.; Koch, C.; Trygstad, T.; Pandit, N. A Study of the Temperature-Dependent Micellization of Pluronic F127. J. Colloid Interface Sci. 1999, 216, 34-40.

(31) Yamamoto, Y.; Yasugi, K.; Harada, A.; Nagasaki, Y.; Kataoka, K. Temperature-Related Change in the Properties Relevant to Drug Delivery of Poly (Ethylene Glycol)- Poly (D,LLactide) Block Copolymer Micelles in Aqueous Milieu. J. Control. Release 2002, 82, 359371.

(32) Fliervoet, L. A. L.; Engbersen, J. F. J.; Schiffelers, R. M.; Hennink, W. E.; Vermonden, T. Polymers and Hydrogels for Local Nucleic Acid Delivery. J. Mater. Chem. B 2018, 6, 5651-5670. https://doi.org/10.1039/c8tb01795f.

(33) Gioffredi, E.; Boffito, M.; Calzone, S.; Maria, S.; Rainer, A.; Trombetta, M.; Mozetic, P.; Chiono, V. Pluronic F127 Hydrogel Characterization and Biofabrication in Cellularized Constructs for Tissue Engineering Applications. Procedia CIRP 2016, 49, 125-132. https://doi.org/10.1016/j.procir.2015.11.001.

(34) Klouda, L.; Mikos, A. G. Thermoresponsive Hydrogels in Biomedical Applications. Eur. J. Pharm. Biopharm. 2008, 68, 34-45. https://doi.org/10.1016/j.ejpb.2007.02.025.

(35) Wu, Y.; Stefl, M.; Olzynska, A.; Hof, M.; Yahioglu, G.; Yip, P.; Casey, D. R.; Ces, O.; Humpolickova, J.; Kuimova, M. K. Molecular Rheometry: Direct Determination of Viscosity in Lo and Ld Lipid Phases via Fluorescence Lifetime Imaging. Phys. Chem. 
Chem. Phys. 2013, 15, 14986-14993. https://doi.org/10.1039/c3cp51953h.

(36) Levitt, J. A.; Kuimova, M. K.; Yahioglu, G.; Chung, P. H.; Suhling, K.; Phillips, D. Membrane-Bound Molecular Rotors Measure Viscosity in Live Cells via Fluorescence Lifetime Imaging. $J . \quad$ Phys. Chem. $\quad C \quad \mathbf{2 0 0 9}, 113$ (27), 11634-11642. https://doi.org/10.1021/jp9013493.

(37) Kuimova, M. K. Mapping Viscosity in Cells Using Molecular Rotors. Phys. Chem. Chem. Phys. 2012, 14, 12671-12686. https://doi.org/10.1039/c2cp41674c.

(38) Chattopadhyay, A.; London, E. Fluorimetric Determination of Critical Micelle Concentration Avoiding Interference from Detergent Charge. Anal. Biochem. 1984, 139, 408-412. https://doi.org/10.1016/0003-2697(84)90026-5.

(39) Kabanov, A. V.; Nazarova, I. R.; Astafieva, I. V.; Batrakova, E. V.; Alakhov, V. Y.; Yaroslavov, A. A.; Kabanov, V. A. Micelle Formation and Solubilization of Fluorescent Probes in Poly(Oxyethylene-b-Oxypropylene-b-Oxyethylene) Solutions. Macromolecules 1995, 28 (7), 2303-2314. https://doi.org/10.1021/ma00111a026.

(40) Singla, P.; Singh, O.; Sharma, S.; Betlem, K.; Aswal, V. K.; Peeters, M.; Mahajan, R. K. Temperature-Dependent Solubilization of the Hydrophobic Antiepileptic Drug Lamotrigine in Different Pluronic Micelles - A Spectroscopic, Heat Transfer Method, Small-Angle Neutron Scattering, Dynamic Light Scattering, and in Vitro Release Study. ACS Omega 2019, 4, 11251-11262. https://doi.org/10.1021/acsomega.9b00939.

(41) Nagarajan, R. Theory of Micelle Formation Quantitative Approach to Predicting Micellar Properties from Surfactant Molecular Structure. In Structure-performance relationships in 
surfactants; Esumi, K., Ueno, M., Eds.; Marcel Dekker, Inc.: New York, 2003; pp 14-122.

(42) Molina-Bolívar, J. A.; Hierrezuelo, J. M.; Carnero Ruiz, C. Energetics of Clouding and Size Effects in Non-Ionic Surfactant Mixtures: The Influence of Alkyl Chain Length and $\mathrm{NaCl}$ Addition. J. Chem. Thermodyn. 2013, 57, 59-66. https://doi.org/10.1016/j.jct.2012.08.002.

(43) Ma, J.; Guo, C.; Tang, Y.; Liu, H. 1H NMR Spectroscopic Investigations on the Micellization and Gelation of PEO-PPO-PEO Block Copolymers in Aqueous Solutions. Langmuir 2007, 23, 9596-9605. https://doi.org/10.1021/la701221f.

(44) George, S.; Kumbhakar, M.; Singh, P. K.; Ganguly, R.; Nath, S.; Pal, H. Fluorescence Spectroscopic Investigation To Identify the Micelle to Gel Transition of Aqueous Triblock Copolymer Solutions. J. Phys. Chem. B 2009, 113, 5117-5127. https://doi.org/10.1021/jp809826c.

(45) Kadam, Y.; Yerramilli, U.; Bahadur, A.; Bahadur, P. Micelles from PEO-PPO-PEO Block Copolymers as Nanocontainers for Solubilization of a Poorly Water Soluble Drug Hydrochlorothiazide. Colloids Surfaces B Biointerfaces 2011, 83 (1), 49-57. https://doi.org/10.1016/j.colsurfb.2010.10.041.

(46) Evans, C. M.; Henderson, K. J.; Saathoff, J. D.; Shull, K. R.; Torkelson, J. M. Simultaneous Determination of Critical Micelle Temperature and Micelle Core Glass Transition Temperature of Block Copolymer-Solvent Systems via Pyrene-Label Fluorescence. Macromolecules 2013, 46, 4131-4140. https://doi.org/10.1021/ma400686j.

(47) Drzal, P. L.; Shull, K. R. Origins of Mechanical Strength and Elasticity in Thermally Reversible, Acrylic Triblock Copolymer Gels. Macromolecules 2003, 36, 2000-2008. 
https://doi.org/10.1021/ma021255v.

(48) Lakowicz, J. R. Principles of Fluorescence Spectroscopy, 3rd ed.; Springer Science+Business Media, LLC: New York, 2006. https://doi.org/10.1007/978-0-38746312-4.

(49) Hopkins, C. C.; de Bruyn, J. R. Gelation and Long-Time Relaxation of Aqueous Solutions of Pluronic F127. J. Rheol. (N. $\quad Y . \quad$ N. $\quad Y$ ). 2019, 63 (1), 191-201. https://doi.org/10.1122/1.5054598.

(50) Chaibundit, C.; Ricardo, N. M. P. S.; Ricardo, N. M. P. S.; Costa, F. de M. L. L.; Wong, M. G. P.; Hermida-Merino, D.; Rodriguez-Perez, J.; Hamley, I. W.; Yeates, S. G.; Booth, C. Effect of Ethanol on the Micellization and Gelation of Pluronic P123. Langmuir 2008, 24 (21), 12260-12266.

(51) Cidade, M. T.; Ramos, D. J.; Santos, J.; Carrelo, H.; Calero, N.; Borges, J. P. Injectable Hydrogels Based on Pluronic/Water Systems Filled with Alginate Microparticles for

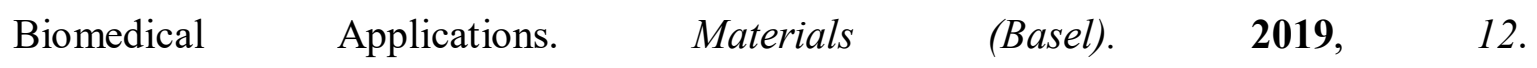
https://doi.org/10.3390/ma12071083.

(52) Kim, S. Y.; Ha, J. C.; Lee, Y. M. Poly(Ethylene Oxide) -Poly (Propylene Oxide)Poly(Ethylene Oxide)/Poly(e -Caprolactone) (PCL) Amphiphilic Block Copolymeric Nanospheres II. Thermo-Responsive Drug Release Behaviors. J. Control. Release 2000, 65, $345-358$.

(53) Pandit, N.; Trygstad, T.; Croy, S.; Bohorquez, M.; Koch, C. Effect of Salts on the Micellization, Clouding, and Solubilization Behavior of Pluronic F127 Solutions. J. 
Colloid Interface Sci. 2000, 222, 213-220. https://doi.org/10.1006/jcis.1999.6628.

(54) Jørgensen, E. B.; Hvidt, S. Effects of Salts on the Micellization and Gelation of a Triblock Copolymer Studied by Rheology and Light Scattering. Macromolecules 1997, 30, 23552364.

(55) Castelletto, V.; Parras, P.; Hamley, I. W.; Bäverbäck, P.; Pedersen, J. S.; Panine, P. Wormlike Micelle Formation and Flow Alignment of a Pluronic Block Copolymer in Aqueous Solution. Langmuir 2007, 23 (13), 6896-6902. https://doi.org/10.1021/la700382y.

(56) Lau, B. K.; Wang, Q.; Sun, W.; Li, L. Micellization to Gelation of a Triblock Copolymer in Water: Thermoreversibility and Scaling. J. Polym. Sci. Part B Polym. Phys. 2004, 42 (10), 2014-2025. https://doi.org/10.1002/polb.20105.

(57) Suntornnond, R.; An, J.; Chua, C. K. Bioprinting of Thermoresponsive Hydrogels for Next Generation Tissue Engineering: A Review. Macromol. Mater. Eng. 2017, 302 (1), 1-15. https://doi.org/10.1002/mame.201600266. 